\title{
Germination and seedling frost tolerance differ between the native and invasive range in common ragweed
}

\author{
Marion Carmen Leiblein-Wild • Rana Kaviani • \\ Oliver Tackenberg
}

Received: 3 April 2013 / Accepted: 21 October 2013 / Published online: 7 November 2013

(c) The Author(s) 2013. This article is published with open access at Springerlink.com

\begin{abstract}
Germination characteristics and frost tolerance of seedlings are crucial parameters for establishment and invasion success of plants. The characterization of differences between populations in native and invasive ranges may improve our understanding of range expansion and adaptation. Here, we investigated germination characteristics of Ambrosia artemisiifolia L., a successful invader in Europe, under a temperature gradient between 5 and $25^{\circ} \mathrm{C}$. Besides rate and speed of germination we determined optimal, minimal and maximal temperature for germination of ten North American and 17 European populations that were sampled along major latitudinal and longitudinal gradients. We furthermore investigated the frost tolerance of seedlings. Germination rate was highest at $15{ }^{\circ} \mathrm{C}$ and germination speed was highest at $25{ }^{\circ} \mathrm{C}$. Germination rate, germination speed, frost tolerance of seedlings, and the temperature niche width for germination were significantly
\end{abstract}

Communicated by Bernhard Schmid.

Electronic supplementary material The online version of this article (doi:10.1007/s00442-013-2813-6) contains supplementary material, which is available to authorized users.

M. C. Leiblein-Wild $(\bowtie)$

Biodiversity and Climate Research Centre (BiK-F),

Senckenberganlage 25, 60325 Frankfurt am Main, Germany

e-mail: mleiblein@senckenberg.de

R. Kaviani · O. Tackenberg

Institute of Ecology, Evolution and Diversity, Goethe University Frankfurt, Max-von-Laue-Strasse 13, 60438 Frankfurt am Main, Germany

Present Address:

R. Kaviani

Michael Succow Foundation for the Protection of Nature,

Ellernholzstrasse, 1/3, 17489 Greifswald, Germany higher and broader, respectively, for European populations. This was partly due to a higher seed mass of these populations. Germination traits lacked evidence for adaptation to climatic variables at the point of origin for both provenances. Instead, in the native range, seedling frost tolerance was positively correlated with the risk of frosts which supports the assumption of local adaptation. The increased frost tolerance of European populations may allow germination earlier in the year which may subsequently lead to higher biomass allocation-due to a longer growing period-and result in higher pollen and seed production. The increase in germination rates, germination speed and seedling frost tolerance might result in a higher fitness of the European populations which may facilitate further successful invasion and enhance the existing public health problems associated with this species.

Keywords Adaptation - Ambrosia artemisiifolia L. · Intraspecific variation $\cdot$ Range expansion $\cdot$ Temperature

\section{Introduction}

Invasive species are regarded as serious threats to global biodiversity (Sala et al. 2000). Their impact is expected to increase with climate change (Thuiller et al. 2006) including increases in species' potential ranges (Kriticos et al. 2003). Thus, predicting the ecology and biogeography of invasive species is of increasing importance. The investigation of crucial life cycle traits and local adaptation is an important basis for understanding the process of range expansion, adaptation (Hierro et al. 2009) and community assembly (Gerhold et al. 2011). Specifically, comparative studies between populations from native and invasive ranges enable more precise conclusions on possible trait 
and niche shifts during the invasion process (Beckmann et al. 2011).

For many plant species, investigations which focus on traits such as growth, flowering phenology, and biomass have been done in either the invasive or native range (Gregor et al. 2013; Kollmann and Banuelos 2004; Montague et al. 2008; Weber and Schmid 1998). Conversely, so far only few comparative studies have considered traits related to germination and early establishment in both invasive and native ranges (Bossdorf et al. 2005).

Germination is of great importance, being the first step in a plant's life cycle, and invasion success has been ascribed, amongst other factors, to high germination rates (Mandak 2003; Radford and Cousens 2000). Particularly for annual species, successful germination is crucial for the establishment of populations and range expansion. In this context, high germination rates and high germination speed are beneficial since successful establishment depends upon rapid exploitation of temporarily favorable conditions (Grime et al. 1981). Since the seedling stage is the most vulnerable time in the life cycle of a plant, the timing of germination is under strong selection: optimally, germination should occur only when the subsequent environmental conditions allow seedling establishment (Rathcke and Lacey 1985).

A trait highly associated with early establishment is frost tolerance of seedlings (Skálová et al. 2011) and many weedy plants are limited in their distribution by frost in temperate zones (Bruelheide and Heinemeyer 2002; Franklin 1995). Especially annual species with a long development period from germination to seed maturity are forced to germinate early in the year and may thus especially be endangered by spring frosts. Seedling frost tolerance may enable survival even after frost exposure. This is particularly relevant for an invader that is expanding its range northeastwards, as is the case in Europe for many plant species (Berger et al. 2007; Parmesan 2006), including also invasive species, e.g., Japanese knotweed (Fallopia japonica) or Cherry laurel (Prunus laurocerasus) (Berger et al. 2007; Dukes and Mooney 1999). However, so far frost tolerance of seedlings in native and invasive ranges has been investigated only rarely (Ebeling et al. 2008; Skálová et al. 2011).

During the process of invasion, genetic bottlenecks, founder effects and a loss of genetic variation commonly occur (Dlugosch and Parker 2008). Therefore, invasive ranges often only represent a subset of the existing variation of a species in a given trait. Consequently, ecological niches in the invaded range may be narrower due to the absence of some genotypes.

On the other hand, invasive species often exhibit a higher fitness in the invasive range compared to their performance in the native range. This finding is often interpreted as either evolutionary [e.g., the evolution of increased competitive ability (EICA) hypothesis (Blossey and Noetzold 1995)] or as an ecological response [e.g., enemy release hypothesis (Keane and Crawley 2002)] to altered abiotic factors or the lack of natural enemies in the invasive range. Higher fitness in the invasive range has been demonstrated for traits like germination, growth, resistance to herbivory etc. in a number of plant species (e.g., Erfmeier and Bruelheide 2005; Beckmann et al. 2011). Other mechanisms, such as selection by the introduction mode, could lead to altered traits in the invaded range. This may be relevant for Ambrosia artemisiifolia, which has been introduced as a seed contaminant and may be dispersed by humans over long distances. Species adapted to human activity may become especially successful invaders (Kowarik 2010). For a review on other hypotheses explaining the success of invasive species see, e.g., Kowarik (2010).

Intraspecific variation, i.e., the variation of characteristics or fitness-related measures between populations of a given species, has been demonstrated for various life history traits (Becker et al. 2006; Joshi et al. 2001), also in invasive ranges (Kollmann and Banuelos 2004; Montague et al. 2008). Such variation is often related to environmental conditions at the points of origin and interpreted as adaptation to these conditions. For germination, environmental factors like spring temperature conditions, altitude (Leger and Rice 2007; Skálová et al. 2011) or soil moisture (Rathcke and Lacey 1985) may be crucial.

In our study, we examined A. artemisiifolia (Asteraceae) as an example of a successful noxious plant invader in Europe. This annual plant species is native to North America where it grows in open grasslands or as competitive weed in crops. The first introduction of $A$. artemisiifolia seeds into Europe occurred in the nineteenth century as contaminants of wheat and other agricultural products from North America (Chauvel et al. 2006; Kowarik 2010). Today, the most important import vector is contaminated birdseed.

A. artemisiifolia grows successfully in crops or in disturbed areas, e.g., road verges or construction areas, in many European countries. The centre of the current distribution in Europe is in Southeastern Europe, the Po valley, and Southern France (Makra et al. 2004). A map of its current distribution is available at Cunze et al. (2013).

The wind-borne pollen of $A$. artemisiifolia may cause hay fever and dermatitis (Taramarcaz et al. 2005) resulting in associated costs of several million euros per year (Reinhardt et al. 2003). A. artemisiifolia only reproduces via seeds, which are viable for up to 39 years (Toole and Brown 1946). Compared to other annual species, A. artemisiifolia needs a long time to fulfil its life cycle: although one of the first annual species to germinate in the year (DiTommaso 2004), the first mature achenes are not expected until 
October (Kazinczi et al. 2008). Due to the requisite early germination, emerging seedlings are particularly endangered by frosts in spring. Mature A. artemisiifolia seeds are dormant and need stratification, normally supplied by winter conditions (Payne and Kleinschmidt 1961). It has been demonstrated that $A$. artemisiifolia populations from different geographic sites may differ in life history traits such as growth and flowering phenology (Hodgins and Rieseberg 2011; Leiblein-Wild and Tackenberg, under review), and that the species is genetically highly diverse (Genton et al. 2005). Therefore, it seems most likely that also a certain degree of variation in germination traits and frost tolerance might exist.

With our experiments we want to contribute to an understanding of the possible changes in germination patterns and frost resistance of invasive species. Especially, we want to enhance our understanding of A. artemisiifolia's range expansion and local adaptation in germination parameters and frost tolerance to environmental conditions. Considering the aspects given above, we tested the following hypotheses with A. artemisiifolia:

1. Germination traits and frost tolerance differ between populations from the invasive (European) and native (North American) range.

2. Germination traits that affect the individual fitness, in particular germination rate and germination speed, are expected to be higher in the invasive range.

3. The germination niche of populations from the invaded range is expected to be narrower, e.g., due to genetic bottlenecks and missing genotypes.

4. Germination traits and frost tolerance are related to environmental variables of the respective point of origin in native and invasive ranges. We expect that the relationships between the considered traits and environmental parameters are stronger in the native range. Although common ragweed in North America is also dispersed by human activities and easily occurs in disturbed habitats, the species has had more time to occupy all possible niches and to adapt better to the respective local climate due to its residential time of many millennia.

\section{Materials and methods}

\section{Germination experiment}

We conducted a germination experiment with A. artemisiifolia populations from the invasive range in Europe and the native range in North America. In 2008 and 2009, seeds from 17 European and ten North American sites were collected. We sampled populations from $34.2^{\circ} \mathrm{N}$ (Georgia) to $44.1^{\circ} \mathrm{N}$ (Wisconsin) latitude and from $-90.0^{\circ} \mathrm{E}$ to $-76.4^{\circ} \mathrm{E}$ longitude in the native range, and from $44.0^{\circ} \mathrm{N}$ (France) to $50.1^{\circ} \mathrm{N}$ (Germany) latitude and from $4.3^{\circ} \mathrm{E}$ (France) to $19.7^{\circ}$ (Hungary) longitude in the invasive range, to cover a broad geographical and environmental gradient. To avoid the use of temporary populations which might not exhibit any adaptation to local conditions, we only used populations from agricultural and ruderal sites that we are relatively sure are established and self-replicating. All points of origin of the populations and their environmental characteristics are listed in Table 1; maps of the sampled locations are given in the Electronic supplementary material (ESM; Fig. A1). Germination of A. artemisiifolia occurs only after seeds break dormancy, which should occur at ca. $4{ }^{\circ} \mathrm{C}$ (Willemsen 1975). Since Pickett and Baskin (1973) demonstrated higher germination rates with increasing length of stratification, we stored the seeds in a fridge at $4{ }^{\circ} \mathrm{C}$ for at least 5 months before starting the experiment.

For each population and temperature regime we used five replicates. Each replicate consisted of 25 or 50 seeds from one population (depending on the available amount of seeds per population; for details see Table 1) which were placed into a petri dish (90 mm diameter; VWR International, Darmstadt, Germany) containing two filter papers wetted with $10 \mathrm{ml}$ deionized water. Each petri dish was put into one of five growth chambers (RUMED, types 3401 and 3501; Rubarth Apparate, Laatzen, Germany) each with a different temperature regime $\left(0 / 10,5 / 15,10 / 20,15 / 25\right.$, and $\left.20 / 30{ }^{\circ} \mathrm{C}\right)$, with a light/dark period of $12 / 12 \mathrm{~h}$ to simulate early spring conditions. In the following, each temperature regime is defined by its mean temperature, e.g., $0 / 10{ }^{\circ} \mathrm{C}$ is termed ' $5{ }^{\circ} \mathrm{C}$ '. The petri dishes were placed randomly inside the growth chambers and rotated regularly. If necessary, deionized water was added to ensure sufficient moisture and the petri dishes were then put back into the respective temperature regime.

Every 5 days the number of germinated seeds was counted for each petri dish and germinated seeds were removed. Seeds were classified as having germinated with the first visible protrusion of the radicle. To account for an observed low germination speed of North American populations and under low temperatures, the test period was set to 60 days.

\section{Germination parameters}

In order to describe the relationship between temperature and germination rate, we primarily used a quadratic function that was fitted separately for each population (Eq. 1),

germination rate $=b_{0}+b_{1} *$ temperature $+b_{2} *$ temperature $^{2}$

with $b_{0}, b_{1}$ and $b_{2}$ being constants that were derived from curve fitting (IBM SPSS Statistics 20). An example of a 
Table 1 Geographic location, species traits and environmental characteristics of European and North American Ambrosia artemisiifolia populations ordered by latitude within the provenances

\begin{tabular}{|c|c|c|c|c|c|c|c|c|c|c|c|}
\hline Pro & State & Region & ID & Latitude $\left(^{\circ}\right)$ & Longitude $\left(^{\circ}\right)$ & G-exp & F-exp & $\begin{array}{l}\text { Seed mass } \\
(\mathrm{mg})\end{array}$ & Temp. $\left({ }^{\circ} \mathrm{C}\right)$ & $\begin{array}{l}\text { Frost risk } \\
\text { (days) }\end{array}$ & Elevation (m) \\
\hline NA & Georgia & Rome & A39 & 34.222 & -85.144 & 25 & 55 & 3.21 & 15.34 & 2.80 & 206 \\
\hline NA & Virginia & Blacksburg & A36 & 35.150 & -81.520 & 25 & 52 & 3.09 & 15.13 & 3.99 & 218 \\
\hline NA & Arkansas & Blytheville & A8 & 35.961 & -89.971 & & 55 & 4.10 & 15.26 & 1.75 & 74 \\
\hline NA & Missouri & Kennett & A9 & 35.998 & -89.994 & 25 & 45 & 3.21 & 15.26 & 1.75 & 74 \\
\hline NA & Virginia & Poquoson & A30 & 37.06 & -76.400 & 25 & 62 & 2.68 & 14.98 & 0.95 & 3 \\
\hline NA & Virginia & Richmond & A28 & 37.713 & -77.466 & 25 & & 3.27 & 13.64 & 5.14 & 63 \\
\hline NA & Virginia & Covington & A27 & 37.811 & -80.071 & & 51 & 4.80 & 11.51 & 9.98 & 601 \\
\hline NA & Missouri & Ste. Genevieve & A10 & 37.918 & -89.993 & 25 & 55 & 6.07 & 13.02 & 5.61 & 116 \\
\hline NA & West Virginia & Marmet & A24 & 38.286 & -81.570 & 25 & 46 & 4.45 & 12.25 & 5.81 & 311 \\
\hline NA & Illinois & Divernon & A12 & 39.567 & -89.716 & & 58 & 6.33 & 11.68 & 6.55 & 194 \\
\hline NA & Indiana & Shirley & A21 & 39.852 & -85.616 & 25 & 59 & 5.97 & 10.43 & 8.75 & 293 \\
\hline NA & Indiana & Remington & A19 & 40.761 & -87.137 & 25 & & 6.78 & 9.84 & 8.33 & 225 \\
\hline NA & Wisconsin & Beloit & A15 & 42.492 & -88.987 & & 63 & 5.13 & 8.29 & 9.84 & 264 \\
\hline NA & Wisconsin & Manitowoc & A16 & 44.052 & -87.658 & 25 & 57 & 5.13 & 7.03 & 10.88 & 182 \\
\hline $\mathrm{E}$ & France & Valliguières & E12 & 44.013 & 4.587 & 50 & 40 & 6.13 & 12.73 & 1.00 & 187 \\
\hline $\mathrm{E}$ & France & Tharaux & E14 & 44.229 & 4.318 & 50 & & 4.14 & 12.48 & 0.93 & 238 \\
\hline $\mathrm{E}$ & France & $\begin{array}{c}\text { Granges-les- } \\
\text { Beaumont }\end{array}$ & E9 & 45.049 & 4.984 & 50 & 37 & 6.67 & 11.95 & 5.64 & 174 \\
\hline $\mathrm{E}$ & France & Meyzieu & E6 & 45.771 & 4.988 & 50 & 38 & 5.13 & 11.49 & 3.22 & 195 \\
\hline $\mathrm{E}$ & Hungary & Ballószög & E27 & 46.883 & 19.557 & 25 & & 4.68 & 10.78 & 3.74 & 114 \\
\hline $\mathrm{E}$ & France & Tart-l'Abbaye & E3 & 47.190 & 5.257 & 50 & 38 & 5.38 & 10.81 & 3.39 & 189 \\
\hline $\mathrm{E}$ & Hungary & Újhartyán & E25 & 47.212 & 19.389 & 25 & 45 & 5.27 & 10.84 & 3.07 & 113 \\
\hline $\mathrm{E}$ & France & Longeault & E2 & 47.217 & 5.529 & 50 & & 4.48 & 10.63 & 3.22 & 221 \\
\hline $\mathrm{E}$ & Hungary & Budapest & E22 & 47.463 & 19.231 & 50 & & 5.30 & 10.73 & 2.91 & 113 \\
\hline $\mathrm{E}$ & Hungary & Bag & E23 & 47.632 & 19.449 & 50 & 38 & 5.94 & 10.43 & 3.26 & 180 \\
\hline $\mathrm{E}$ & Hungary & Hatvan & E24 & 47.671 & 19.672 & 50 & & 6.17 & 10.40 & 3.98 & 119 \\
\hline $\mathrm{E}$ & Germany & Karlsruhe & E17 & 49.044 & 8.393 & 25 & 39 & 4.00 & 10.44 & 3.63 & 107 \\
\hline $\mathrm{E}$ & Germany & St. Leon-Rot & E19 & 49.261 & 8.591 & 25 & & 6.16 & 10.38 & 3.82 & 109 \\
\hline $\mathrm{E}$ & Germany & Mannheim & E20 & 49.534 & 8.466 & 25 & 39 & 10.28 & 10.12 & 4.35 & 94 \\
\hline $\mathrm{E}$ & Germany & Pfungstadt & E30 & 49.794 & 8.606 & 50 & 37 & 7.37 & 9.83 & 3.98 & 233 \\
\hline $\mathrm{E}$ & $\begin{array}{l}\text { Czech Repub- } \\
\text { lic }\end{array}$ & Prague & E34 & 50.087 & 14.472 & 25 & 38 & 4.17 & 8.88 & 7.78 & 244 \\
\hline $\mathrm{E}$ & Germany & Höchst & E29 & 50.091 & 8.553 & 25 & & 4.78 & 9.78 & 4.61 & 104 \\
\hline $\mathrm{E}$ & Germany & Sassleben & E32 & 51.754 & 13.973 & & 39 & 6.91 & 9.20 & 7.12 & 94 \\
\hline
\end{tabular}

Pro provenance, NA North America, E Europe, $I D$ identification code of each population, G-exp number of seeds per petri dish used in the germination-tolerance experiment, $F$-exp number of seeds used in the frost-tolerance experiment, Temp. mean annual temperature (data source: worldclim.org), Frost risk mean number of days with frost between March and May [data sources: European Climate Assessment and Dataset (Haylock et al. 2008), National Climatic Data Center of the National Oceanic and Atmospheric Administration]

quadratic function is shown in the ESM, Fig. A2. From these quadratic functions (which were only interpreted for positive germination rates), we directly calculated the following parameters that were used to characterize germination of each population in the subsequent analyses:

- Minimal temperature for germination $\left(T_{\min }\right)$

- Optimal temperature for germination $\left(T_{\mathrm{opt}}\right)$
- Maximal temperature for germination $\left(T_{\max }\right)$

- Niche width of the germination temperature $\left(T_{\text {range }}\right)$

- Maximal germination rate $\left(G_{\max }\right)$

$T_{\max }$ and $T_{\min }$ were calculated via setting the quadratic function to zero, $T_{\mathrm{opt}}$ was calculated as the temperature value at the vertex of the respective quadratic function, and $G_{\max }$ was calculated as the peak germination rate at the vertex. $T_{\text {range }}$ was calculated as $T_{\max }-T_{\text {min }}$. 
Furthermore, we used the time of $50 \%$ germination (T50), i.e., the number of days when $50 \%$ of seeds have germinated, to characterize the germination speed. T50 was calculated separately for each temperature and population: In order to get a measure of germination speed, which is independent from the total amount of seeds that finally germinate, the cumulative number of germinated seeds after 60 days of the respective population and temperature regime was defined as $100 \%$ and T50 was calculated using linear interpolation (ESM, Fig. A3).

\section{Frost-tolerance experiment}

To investigate the frost tolerance of A. artemisiifolia seedlings, we used seedlings from 11 European and 12 North American populations. If possible, we used the same populations as in the germination experiment. In the case of a lack of seed material, we used seed material of populations from similar latitudes (Table 1). For each population we germinated around 50 seeds under optimal $\left(20 / 10^{\circ} \mathrm{C}\right)$ temperature conditions with a $12 / 12 \mathrm{~h}$ dark/daylight cycle in a growth chamber (RUMED, type 3501; Rubarth Apparate).

After germination, seedlings were transplanted into seedling trays filled with propagating substrate $(100 \mathrm{mg}$ $\mathrm{N}^{-1}, 100 \mathrm{mg} \mathrm{P}_{2} \mathrm{O}_{5} \mathrm{l}^{-1}, 150 \mathrm{mg} \mathrm{K}_{2} \mathrm{O} \mathrm{l}^{-1}, 60 \mathrm{mg} \mathrm{Mg}^{-1}$; C200; Stender, Schermbeck, Germany) and cultivated under the same temperature conditions until the appearance of the first pair of secondary leaves. Then the frost treatment was conducted. First, the temperature inside the climate chamber was set to $2{ }^{\circ} \mathrm{C}$ for $9 \mathrm{~h}$ to avoid temperature shock and to allow some acclimatization. Second, the temperature was decreased to $-5{ }^{\circ} \mathrm{C}$ for $6 \mathrm{~h}$ to simulate night frosts in spring. Third, seedlings were cultivated at $2{ }^{\circ} \mathrm{C}$ again for $9 \mathrm{~h}$, before returning to the optimal temperature conditions $\left(20 / 10{ }^{\circ} \mathrm{C}\right)$. The next day, the state of each seedling (dead or damaged versus undamaged) was inspected visually and completely undamaged seedlings were classified as 'frost tolerant'. In total we exposed around 50 seedlings per population (mean $=48, \mathrm{SD}=9.2$; Table 1 ). From these data the proportion of frost-tolerant seedlings was determined for each population.

Environmental variables at the point of origin

We considered environmental variables, such as temperature and the risk of frost exposure in spring, from the respective point of origin of the population. Monthly mean temperature values of current conditions (1950-2000) were derived from the WorldClim global climate database (www .worldclim.org/11.10.2010) with a spatial resolution of $1 \mathrm{~km}^{2}$. We used annual mean temperature in the analyses which, for our dataset, was highly correlated with the mean temperature in spring, when $A$. artemisiifolia germination takes place (Spearman $\rho=0.755, P<0.001$ ).

Data on frost occurrences during spring in Europe were derived from the European Climate Assessment and Dataset (Haylock et al. 2008) with a spatial resolution of $25 \mathrm{~km}^{2}$. The respective data for North America with a similar geographical resolution were derived from the National Climatic Data Center of the National Oceanic and Atmospheric Administration. We calculated the average number of days with a minimal temperature below $0{ }^{\circ} \mathrm{C}$ for each month between 1950 and 2012. The mean number of days per year with frost between March and May, i.e., the typical germination period of $A$. artemisiifolia (Kazinczi et al. 2008), was calculated for each point of origin and used as measure of the risk of spring frost exposure in the analyses. We also included latitude and longitude as explanatory variables. Latitude is highly associated with the length of day, which plays an important role in other stages of the ragweed life cycle, e.g., onset of flowering (Deen et al. 1998). Longitude may be seen as a rough measure of continentality, at least in Europe.

\section{Seed mass}

For all populations used in the frost-tolerance experiment and the germination experiment, seed mass was determined. We took 50 randomly chosen seeds per population which were weighed simultaneously (CPA225D; Sartorius, Germany). Taking five replicates (consisting of 50 seeds) per population we calculated the mean mass for one individual seed.

\section{Statistical analysis}

Differences in frost tolerance and germination traits (T50 at different temperature regimes, cumulative germination rates, $T_{\min }, T_{\mathrm{opt}}, T_{\max }$, and $G_{\max }$ ) between populations from the native and the invasive range were compared with a Mann-Whitney $U$-test.

As we found that mean seed mass differed between North American and European populations, we conducted an analysis of covariance (ANCOVA) to separate the effect of provenance and seed mass. Requirements for ANCOVA (normality of residuals, homoscedasticity) were given.

The relationship of germination traits and frost tolerance of $A$. artemisiifolia populations with the environmental variables and seed mass were calculated using Spearman rank correlations.

To compare the strength of correlations between native and invasive ranges, the analyses were conducted for each provenance (North America vs. Europe) separately. 
All tests were computed with SPSS 20 (SPSS; Chicago, IL) or R (version 2.11.1; R Development Core Team 2011).

\section{Results}

Germination traits of European and North American populations

A. artemisiifolia $\mathrm{L}$. germination occurred under all imposed temperature conditions between 5 and $25^{\circ} \mathrm{C}$, but T50 and germination rates differed considerably between the single temperature regimes: cumulative germination rates were highest under $15{ }^{\circ} \mathrm{C}$ conditions for populations from both provenances (Fig. 1a). Above and below this optimal temperature regime, germination rates decreased in populations from both ranges similarly (Fig. 1a). Under all five temperature regimes, cumulative germination of European populations was higher than in North American populations (Mann-Whitney $U$-test, $P<0.05$; Fig. 1a).

T50 was lowest under $25{ }^{\circ} \mathrm{C}$ temperature conditions (mean of North American and European populations $=13.4$ days) and increased continuously with decreasing temperature (Fig. 1b). T50 was significantly higher in North American populations than in European populations under each temperature (Table 2). Under low temperatures, seeds from the native range needed 5.9 days longer than seeds from the invasive range to achieve $50 \%$ germination. Under optimal temperatures $\left(15{ }^{\circ} \mathrm{C}\right)$ they needed 24.0 days longer, and under high temperatures $\left(25^{\circ} \mathrm{C}\right)$ the delay was 17.8 days.

The quadratic models explaining the relationship between temperature and cumulative germination were highly significant $(P<0.001)$ and displayed very high $R^{2}$-values (mean $=0.82 \pm 0.08 ; \mathrm{ESM}$, Table A1) for each population. Thus the models seem appropriate to calculate the derived statistics $T_{\min }, T_{\mathrm{opt}}, T_{\max }$ and $G_{\max }$.

$T_{\text {opt }}$ varied from 13.8 to $21.8{ }^{\circ} \mathrm{C}$ and did not differ significantly between native and invasive provenances (Table 2). $T_{\max }$ ranged from 23.6 to $40.3{ }^{\circ} \mathrm{C}$ and was significantly higher in populations from the invasive range (Table 2). $T_{\min }$ was on average $3.1{ }^{\circ} \mathrm{C}$ and significantly lower in populations from the invasive range (Table 2). Consequently, the temperature niche ( $\left.T_{\text {range }}\right)$ was significantly higher in populations from the invasive range than in native ones (Table 2). $G_{\max }$ averaged over all populations was $70.1 \%$ and was significantly higher for populations from the invasive range (Table 2). Seeds used in the germination experiment tended to be heavier in the invasive range compared to the native range, although the difference was not quite statistically significant (Table 2).
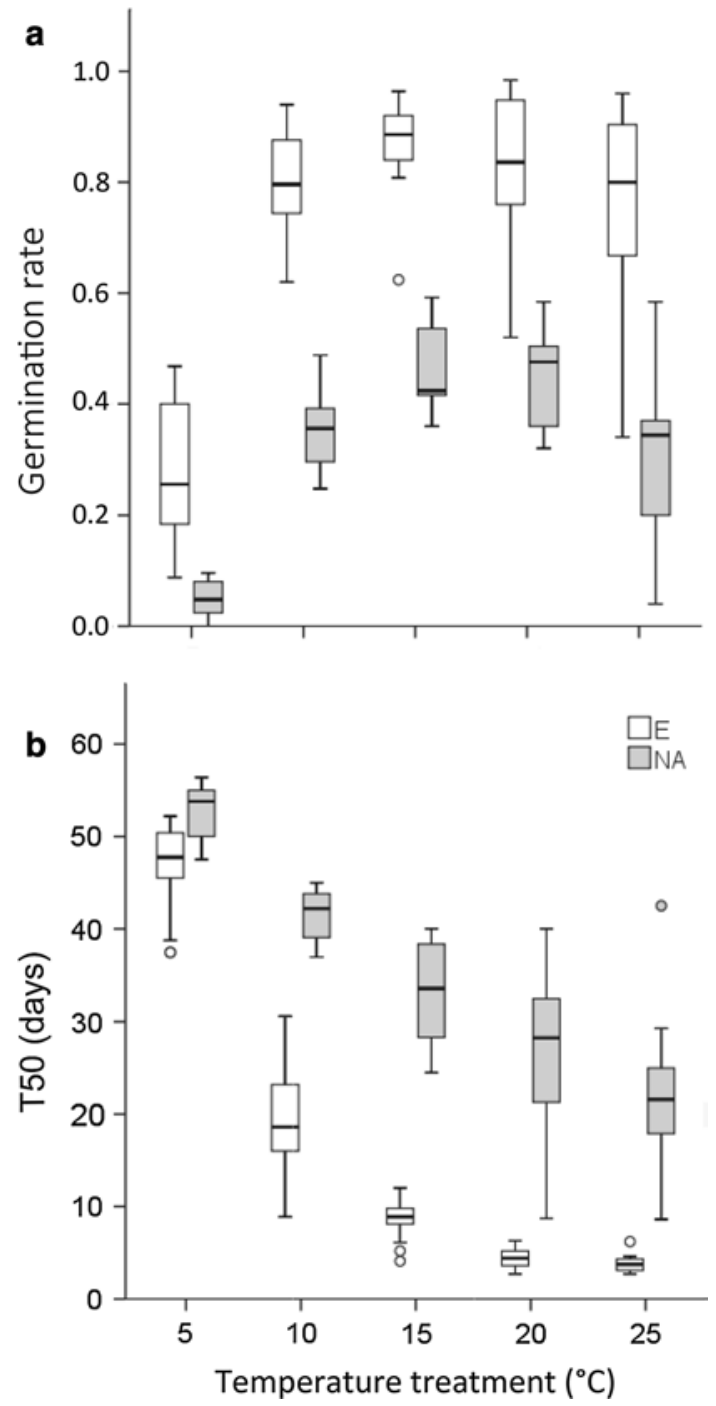

Fig. 1 Box and whisker plots (whiskers with maximum 1.5 interquartile range) showing effects of temperature on germination of North American and European Ambrosia artemisiifolia populations. a Cumulative germination rates after 60 days and $\mathbf{b}$ number of days required to achieve $50 \%$ of final germination (T50) of North American $(N A ; n=10)$ and European $(E ; n=17)$ populations

Frost tolerance of European and North American populations

Frost tolerance, i.e., the proportion of undamaged seedlings after frost treatment in the climate chamber, was higher in European $(37.0 \pm 12.8 \%)$ than in North American populations $(23.3 \pm 7.8 \%$, Mann-Whitney $U$-test, $P=0.003$; Table 2). Frost tolerance was less variable within the native A. artemisiifolia populations (12.9 to $36.8 \%$ ) compared to that of European populations, which varied from 7.9 to $56.8 \%$. The mass of seeds used in this experiment was significantly higher for the invasive than for the native range (Table 2). 
Table 2 Differences in germination traits, frost-tolerance traits and seed mass of $A$. artemisiifolia from native (North American) and invasive (European) ranges

\begin{tabular}{lcccr}
\hline Parameter & \multicolumn{2}{l}{ Provenance } & \multicolumn{2}{l}{$P$} \\
\cline { 2 - 3 } & Native range $^{\mathrm{a}}$ & Invasive range $^{\mathrm{a}}$ & & \\
\hline$T_{\min }\left({ }^{\circ} \mathrm{C}\right)$ & $4.2 \pm 0.63$ & $2.0 \pm 1.18$ & 165 & $<0.001$ \\
$T_{\text {max }}\left({ }^{\circ} \mathrm{C}\right)$ & $30.6 \pm 5.26$ & $34.6 \pm 4.55$ & 45.5 & 0.046 \\
$T_{\text {opt }}\left({ }^{\circ} \mathrm{C}\right)$ & $17.4 \pm 2.71$ & $18.3 \pm 2.13$ & 65 & 0.334 \\
$T_{\text {range }}\left({ }^{\circ} \mathrm{C}\right)$ & $26.4 \pm 5.19$ & $32.5 \pm 5.11$ & 36 & 0.013 \\
$G_{\text {max }}(\%)$ & $48.9 \pm 13.07$ & $91.3 \pm 11.60$ & 3 & $<0.001$ \\
T50_5 (days) & $52.6 \pm 3.46$ & $46.8 \pm 4.94$ & 128 & 0.004 \\
T50_10 (days) & $41.7 \pm 2.84$ & $19.2 \pm 5.45$ & 170 & $<0.001$ \\
T50_15 (days) & $33.3 \pm 5.44$ & $9.3 \pm 3.64$ & 170 & $<0.001$ \\
T50_20 (days) & $26.3 \pm 9.28$ & $5.2 \pm 3.53$ & 168 & $<0.001$ \\
T50_25 (days) & $22.2 \pm 9.24$ & $4.5 \pm 2.72$ & 168 & $<0.001$ \\
Frost tolerance $(\%)$ & $23.3 \pm 7.8$ & $37.0 \pm 12.8$ & 114.5 & 0.003 \\
Seed mass G-exp & $4.4 \pm 1.50$ & $5.7 \pm 1.52$ & 46 & 0.052 \\
$\quad(\mathrm{mg})$ & & & & \\
Seed mass F-exp & $4.5 \pm 1.27$ & $6.1 \pm 1.74$ & 29 & 0.023 \\
$\quad$ (mg) & & & & \\
\hline
\end{tabular}

Seed mass is shown for the subset of populations used in the germination experiment (G-exp) and for the subset used in the frost-tolerance experiment (F-exp)

$T_{\min }$ minimal temperature for germination, $T_{\max }$ maximal temperature for germination, $T_{\text {opt }}$ optimal temperature for germination, $T_{\text {range }}$ niche width of the germination temperature, $G_{\max }$ maximal germination rate, $T 50$ time at which $50 \%$ germination is achieved

${ }^{\text {a }}$ Mean values $\pm \mathrm{SD}$

The influence of seed mass on germination traits and frost tolerance

On average, seed mass was higher for populations from the invasive range (significantly higher for the subset of populations used in the frost-tolerance experiment and higher by trend for the subset of populations used in the germination experiment). To account for the possible influence of seed mass, data on germination traits and frost tolerance were analyzed using ANCOVA to separate the effect of provenance and seed mass. Besides provenance, seed mass also had a significant effect on $G_{\text {max }}, T_{\text {max }}, T_{\text {range }}$, and frost tolerance of seedlings (Table 3).
The positive correlation between seed mass and $G_{\max }$, as well as the correlation between seed mass and frost tolerance, are shown as exemplary (Fig. 2). However, usually more variance was explained by the provenance (Table 3 ). Seed mass had no influence on $T_{\min }$ and T50, which differed significantly between the native and invasive range (Table 3 ).

Correlations of germination traits and frost tolerance with geographical and climatic variables

For the native range, most germination traits were not correlated with any of the considered environmental parameters (Table 4). Only $G_{\max }$ was negatively correlated with longitude, indicating that populations from eastern, more oceanic provenances, exhibit lower germination rates. For the invasive range, we found no correlation of germination traits with geographical and climatic variables (Table 4).

Frost tolerance of seedlings was strongly positively correlated with the risk of frost occurrence in spring for the native range (Fig. 3; Table 4). For populations from the invasive range, no correlation of frost tolerance with environmental parameters was found.

\section{Discussion}

Temperature demands for germination

We investigated the germination of A. artemisiifolia along a temperature gradient from 5 to $25^{\circ} \mathrm{C}$ and found that germination occurred under all temperature regimes. $T_{\text {opt }}$ did not differ between European and North American populations and ranged from 13.8 to $21.8^{\circ} \mathrm{C}$ with most populations having an optimum between 16 and $17{ }^{\circ} \mathrm{C}$. These results are in accordance with observations from Brandes and Nitzsche (2007) who found an optimal germination temperature between 15 and $25{ }^{\circ} \mathrm{C}$. While Forcella et al. (1997) observed $13{ }^{\circ} \mathrm{C}$ as a minimum temperature for $A$. artemisiifolia germination, we demonstrated a lower minimal temperature: in our experiment, seeds germinated at temperatures of $5{ }^{\circ} \mathrm{C}$ (lowest temperature regime). The calculated $T_{\text {min }}$ values $\left(\right.$ mean $=3.1^{\circ} \mathrm{C}$ ) for germination are in accordance with Guillemin et al.

Table 3 Effect of provenance (North America versus Europe) and seed mass on germination traits and frost tolerance of seedlings tested using analysis of covariance

\begin{tabular}{|c|c|c|c|c|c|c|c|c|c|c|c|c|c|c|c|c|}
\hline & \multicolumn{3}{|c|}{$T_{\min }$} & \multicolumn{2}{|l|}{$T_{\mathrm{opt}}$} & \multicolumn{2}{|l|}{$T_{\max }$} & \multicolumn{2}{|l|}{$G_{\max }$} & \multicolumn{2}{|l|}{$T_{\text {range }}$} & \multicolumn{2}{|l|}{ T50_15 } & \multicolumn{3}{|c|}{ Frost tolerance } \\
\hline & $d f$ & $F$ & $P$ & $F$ & $P$ & $F$ & $P$ & $F$ & $P$ & $F$ & $P$ & $F$ & $P$ & $d f$ & $F$ & $P$ \\
\hline Provenance & 1 & 26.97 & $<0.001$ & 1.39 & 0.250 & 5.66 & 0.026 & 84.76 & $<0.001$ & 10.78 & 0.003 & 194.67 & $<0.001$ & 1 & 12.21 & 0.002 \\
\hline Seed mass & 1 & 0.46 & 0.503 & 12.16 & 0.002 & 9.46 & 0.005 & 4.42 & 0.047 & 6.78 & 0.016 & 2.68 & 0.115 & 1 & 7.26 & 0.014 \\
\hline Residuals & 23 & & & & & & & & & & & & & 19 & & \\
\hline
\end{tabular}

For abbreviations, see Table 2 
Fig. 2 Relationship between a germination rate $\left(G_{\max }\right)$ with seed mass (native range, Spear$\operatorname{man} \rho=0.624, P=0.054$, $n=10$; invasive range, $\rho=0.340, P=0.181, n=17$ ) and $\mathbf{b}$ frost tolerance with seed mass (native range, $\rho=0.378$, $P=0.225, n=12$; invasive range, $\rho=0.636, P=0.035$, $n=11$ ) for A. artemisiifolia populations from native and invasive ranges

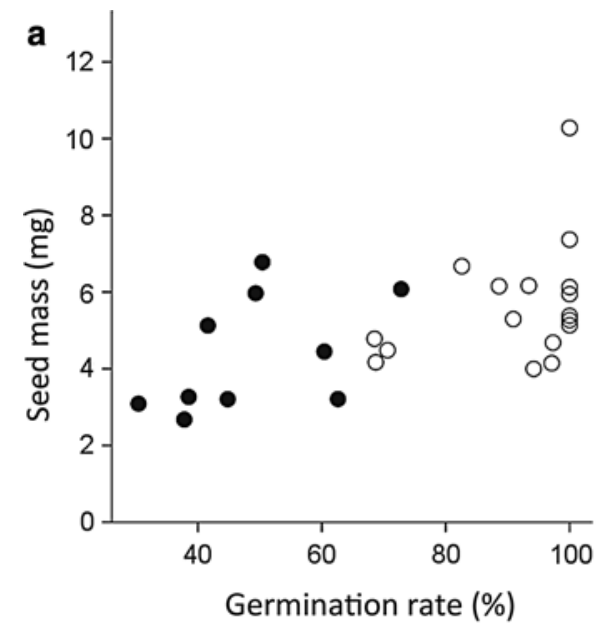

Table 4 Correlation coefficients (Spearman $\rho$ ) of germination traits and frost tolerance of $A$. artemisiifolia populations with environmental parameters of the point of origin for the native and invasive range

\begin{tabular}{lccccc}
\hline Trait & Latitude & Longitude & Temperature & Frost risk & $n$ \\
\hline \multicolumn{7}{c}{ Native range } \\
\multicolumn{2}{l}{ (North America) } & & & \\
$T_{\min }$ & 0.429 & -0.288 & -0.472 & 0.436 & 10 \\
$T_{\max }$ & 0.539 & -0.527 & -0.479 & 0.479 & 10 \\
$T_{\text {opt }}$ & 0.539 & -0.527 & -0.479 & 0.479 & 10 \\
$G_{\max }$ & 0.261 & $-0.758^{*}$ & -0.164 & 0.212 & 10 \\
T50_15 & -0.309 & 0.188 & 0.358 & -0.455 & 10 \\
FT & 0.322 & 0.084 & $-0.526 \dagger$ & $0.726^{* * *}$ & 12 \\
Invasive range (Europe) & & & & \\
$T_{\min }$ & 0.301 & 0.124 & -0.252 & 0.115 & 17 \\
$T_{\max }$ & -0.324 & -0.151 & 0.318 & -0.356 & 17 \\
$T_{\text {opt }}$ & -0.227 & -0.150 & 0.238 & -0.352 & 17 \\
$G_{\max }$ & -0.340 & -0.041 & 0.353 & -0.417 & 17 \\
T50_15 & -0.339 & -0.398 & 0.280 & -0.086 & 17 \\
FT & 0.000 & 0.273 & 0.018 & -0.364 & 11 \\
\hline
\end{tabular}

FT Frost tolerance, $\rho$ Spearman correlation coefficient, $n$ number of populations; for other abbreviations, see Table 1

$\dagger P<0.1, * P<0.05, * * P<0.01$

(2013) who found a base temperature of $3.6^{\circ} \mathrm{C}$ for A. artemisiifolia germination. These low $T_{\min }$ values may promote early germination in spring and thus prolong the growing season for this late-flowering annual. Furthermore, low $T_{\min }$ values should enable germination to occur even far north of the current distribution limit (Cunze et al. 2013) of the species.

Differences in germination traits between populations from the native and invasive ranges and the influence of seed mass

$G_{\max }$ and T50 differed significantly between the native and the invasive range, with considerably higher germination

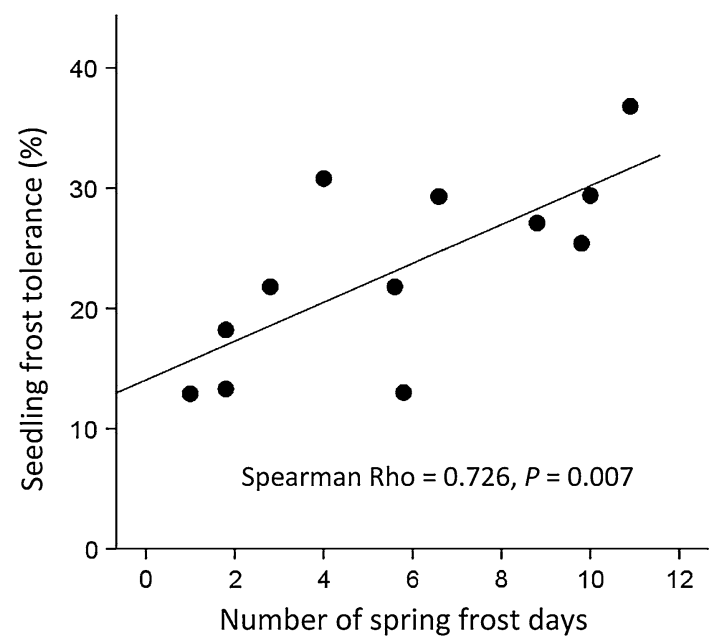

Fig. 3 Frost tolerance of seedlings for North American A. artemisiifolia populations in relation to the risk of spring frosts at the respective point of origin, $n=12$

speed and higher germination rates in the populations from the invasive range. With seedling establishment being a critical stage in plants' life cycles (Donohue et al. 2010), especially individuals with fast germination and high germination rates may be able to compete with other species more effectively. High germination rates contribute significantly to invasion success (Mandak 2003; Radford and Cousens 2000).

Also for other species, differences in germination traits between native and introduced populations were found (reviewed in Donohue et al. 2010). In some cases, the introduced populations had a wider range of conditions under which germination was possible, or they germinated faster (Blair and Wolfe 2004; Cervera and Parra-Tabla 2009; Erfmeier and Bruelheide 2005), which we also observed for A. artemisiifolia. This finding can be explained with the EICA hypothesis: in invasive ranges other biotic or abiotic 
factors often support invasive species compared with factors in the native ranges (Hierro et al. 2005) or natural enemies or pathogens that are missing (Blossey and Noetzold 1995), which enables individuals to perform better and, e.g., invest more in the seeds. This again may be the result of advantageous germination properties of the seeds (e.g., increased germination rates). Accordingly, for A. artemisiifolia, seed mass was on average higher in populations from the invasive range and had an influence on $T_{\max }, G_{\max }$ and frost tolerance. We conclude that the increased seed mass of the European populations contributes to their higher germination rates, increased seedling frost tolerance and higher $T_{\max }$ values. However, the lower $T_{\min }$ values and higher germination speed found in the invasive range cannot be explained by the increased seed mass.

In populations from the invasive range, $T_{\min }$ was on average lower, and $T_{\max }$ was higher, which results in an increased $T_{\text {range }}$ for germination. This finding is in contrast to our expectation of a narrower niche in the European populations due to the potential absence of some genotypes which did not make it to Europe. A wider germination niche may correspond to a wider ecological niche or range, but this is controversial in the literature (Donohue et al. 2010). One possible explanation for the increased temperature niche is that we have evidence for multiple introductions of $A$. artemisiifolia from various points of origin (Genton et al. 2005; Gladieux et al. 2011), which may cause increased genetic and phenotypic variability. Recent studies on the invasive Bromus tectorum indicate that range expansion in the invasive range might be facilitated by the introduction of specialized genotypes (Merrill et al. 2012).

Alternatively, an increased temperature niche may have evolved as an adaptation to changed selection pressures in the invasive ranges. It has been suggested that traits linked with germination may evolve quickly (Donohue et al. 2010), and successful invasive species are able to evolve in response to novel selection pressure and radiate into diverse habitats (Sakai et al. 2001). Fast evolution may be facilitated by increased genetic diversity and additive genetic variance resulting from admixture of populations from different sources and multiple introduction events (Ellstrand and Schierenbeck 2000; Lavergne and Molofsky 2007; Lee 2002; Prentis et al. 2008).

Overall, we estimate that the invasive A. artemisiifolia populations are exhibiting traits that may result in a higher fitness: faster germination, a broader germination temperature niche, and higher germination rates. Also Hodgins and Rieseberg (2011) demonstrated a higher fitness for many growth characteristics for European A. artemisiifolia populations compared to North American populations. These authors suggest an adaptation to more competitive environments in the invasive range.
Relationship between germination temperature demands and environmental variables

For many life history traits, such as flowering phenology and reproductive biomass, latitudinal clines have been reported for A. artemisiifolia for native and invasive ranges (Chun et al. 2011; Hodgins and Rieseberg 2011; LeibleinWild and Tackenberg, under review). However, in contrast to our expectation, we hardly found any evidence for the hypothesis that germination traits of A. artemisiifolia are related to environmental variables of the respective point of origin, neither in the native nor in the invasive range. The missing significance may be partly attributed to the small number of populations used in the germination experiment. On the other hand, for frost tolerance, we found strong and significant correlations with environmental variables using a comparable sample size. Possibly, local microclimatic conditions differing from the mean climate in the area are more relevant for germination traits. Therefore, the use of mean climatic values for the statistical analysis may have resulted in non-significant effects on germination traits. For other (weedy) plant species, correlations between germination traits and temperature at the point of origin were found (De Frenne et al. 2009; Xia et al. 2011). In contrast, we have no evidence for local adaptation of germination parameters to the climate in A. artemisiifolia. However, besides the climatic environment, also maternal effects or other environmental variables at the points of origin (e.g., soil conditions, biotic factors etc.) may influence seed germination of the offspring, but such factors have not been investigated in our study.

On the other hand, the broad temperature niche for germination (mean $=30.5{ }^{\circ} \mathrm{C}$ ) given for each single population, and relatively high germination rates even under less favorable temperatures, might compensate for a lack of adaptation to specific temperatures prevailing at the points of origin. Moreover, selection due to other environmental factors may be stronger: possibly for annual late-flowering species selection to seedling frost tolerance-for which we found a very strong correlation with climatic parametersis more important than adaptations in germination temperatures, specifically in northern and temperate latitudes.

\section{Frost tolerance of seedlings}

Generally, the mortality of seedlings exposed to frost was relatively high but comparable to those of different Impatiens species (Skálová et al. 2011). Frost tolerance of European populations was significantly higher, maybe due to the higher seed mass, which was positively related to seedling frost tolerance. This increased frost tolerance may be helpful for the north and eastwards range expansion since frost tolerance of seedlings is highly associated with the 
establishment phase of invasion (Skálová et al. 2011). An increased frost tolerance may enable early germinating individuals to survive late frost and to gain an advantage in fitness over late germinating individuals: early germination is accompanied by a prolongation of the growing period and may thus increase biomass accumulation. This may result in a higher pollen load and increased seed production, since these parameters are positively correlated with biomass in A. artemisiifolia (Fumanal et al. 2007). For example, A. artemisiifolia individuals that germinate in April achieve a final height of $170-180 \mathrm{~cm}$ and produced 3,000-4,000 achenes. For seeds germinating in August, the plant height is $10 \mathrm{~cm}$ with only 4.5 achenes produced (Dickerson and Sweet 1971; Kazinczi et al. 2008).

Relationship between frost tolerance and environmental variables

Frost tolerance was correlated with the frost risk at the point of origin for North American populations. The extraordinarily high correlation coefficient (Spearman $\rho=0.73, P=0.007$ ) points to an important role of frost for the establishment of A. artemisiifolia. For many plant species frost resistance is correlated with local climatic conditions in the native range (Bannister and Polwart 2001), suggesting that populations from the native range have evolved frost tolerance as an evolutionary response to survive frost.

For European populations we found that frost tolerance differed between the populations, but was not correlated to the frost risk or temperature of the point of origin. Similarly, for Buddleja davidii, another invasive plant species, frost tolerance in the invasive range could not be related to geographic or climatic parameters at the point of origin of the populations (Ebeling et al. 2008). This obvious lack of local adaptation to low temperatures in the European populations probably reflects the fact that A. artemisiifolia is relatively new to Europe.

\section{Conclusion}

We demonstrated that $A$. artemisiifolia germination takes place along a broad temperature gradient with high germination rates even under low temperatures, which may promote a high number of offspring nearly irrespective of the temperature at a given site. Different temperature demands for the germination of A. artemisiifolia between populations from invasive and native ranges indicate an expansion of the germination temperature niche in European populations which might be one reason for the species' invasion success in Europe. Generally, seeds from European sites showed an increased fitness and robustness, i.e., higher germination rates, faster germination, and increased frost tolerance; all of these aspects favoring invasion success. The higher seed mass in the invasive range contributed to enhanced germination rates and higher $T_{\max }$ values, but did not contribute in the lower $T_{\min }$ values and higher germination speed of European ragweed populations. The lower $T_{\min }$ values associated with the increased frost tolerance of seedlings in the European populations may enable germination earlier in the year. This again might subsequently lead to higher biomass allocation due to a longer growing period (Donohue et al. 2010), which may be connected with an increased pollen and seed production (Fumanal et al. 2007). As a consequence, the existing medical problems with this highly invasive species might become more acute in Europe, and further invasion in Europe might be facilitated. As niche models predict an enlargement of suitable habitats for A. artemisiifolia under climate change conditions (Cunze et al. 2013), eradication measures should be intensified.

Acknowledgments The present study was conducted at the Biodiversity and Climate Research Centre (BiK-F), Frankfurt am Main, and was funded by the LOEWE-Landes-Offensive zur Entwicklung wissenschaftlich-ökonomischer Exzellenz program of Hesse's Ministry of Higher Education, Research, and the Arts. We thank Stefan and Anne Koller, Cornelia Bäucker, Jitka Klimesova and Felix Heydel for contributing A. artemisiifolia seed material. We acknowledge the E-OBS dataset from the EU-FP6 project ENSEMBLES (http://ensembles-eu.metoffice.com) and the data providers in the ECA\&D project (http://www.ecad.eu). We acknowledge Sarah Cunze and Christoph Brendle for help in the processing of environmental data, and Daniel Jordan Grobbel-Rank for the improvement of the English. Constructive suggestions of reviewers of previous versions of the manuscript greatly improved the present paper. The experiments comply with the current laws in Germany. The authors declare that they have no conflict of interest.

Open Access This article is distributed under the terms of the Creative Commons Attribution License which permits any use, distribution, and reproduction in any medium, provided the original author(s) and the source are credited.

\section{References}

Bannister P, Polwart A (2001) The frost resistance of ericoid heath plants in the British Isles in relation to their biogeography. J Biogeogr 28:589-596

Becker U, Colling G, Dostal P, Jakobsson A, Matthies D (2006) Local adaptation in the monocarpic perennial Carlina vulgaris at different spatial scales across Europe. Oecologia 150:506-518

Beckmann M, Bruelheide H, Erfmeier A (2011) Germination responses of three grassland species differ between native and invasive origins. Ecol Res 26:763-771

Berger S, hlke G, Walther G-R, Pott R (2007) Bioclimatic limits and range shifts of cold-hardy evergreen broad-leaved species at their northern distributional limit in Europe. Phytocoenologia 37:523-539

Blair AC, Wolfe LM (2004) The evolution of an invasive plant: an experimental study with Silene latifolia. Ecology 85: 3035-3042 
Blossey B, Noetzold R (1995) Evolution of increased competitive ability in invasive nonindigenous plants: a hypothesis. J Ecol 83:887-889

Bossdorf O, Auge H, Lafuma L, Rogers WE, Siemann E, Prati D (2005) Phenotypic and genetic differentiation between native and introduced plant populations. Oecologia 144:1-11

Brandes D, Nitzsche J (2007) Verbreitung, Ökologie und Soziologie von Ambrosia artemisiifolia L. in Mitteleuropa. Tuexenia 27:167-194

Bruelheide H, Heinemeyer A (2002) Climatic factors controlling the eastern and altitudinal distribution boundary of Digitalis purpurea L. in Germany. Flora 197:475-490

Cervera JC, Parra-Tabla V (2009) Seed germination and seedling survival traits of invasive and non-invasive congeneric Ruellia species (Acanthaceae) in Yucatan, Mexico. Plant Ecol 205:285-293

Chauvel B, Dessaint F, Cardinal-Legrand C, Bretagnolle F (2006) The historical spread of Ambrosia artemisiifolia L. in France from herbarium records. J Biogeogr 33:665-673

Chun YJ, Le Corre V, Bretagnolle F (2011) Adaptive divergence for a fitness-related trait among invasive Ambrosia artemisiifolia populations in France. Mol Ecol 20:1378-1388

Cunze S, Leiblein MC, Tackenberg O (2013) Range expansion of Ambrosia artemisiifolia in Europe is promoted by climate change. ISRN Ecology. doi:10.1155/2013/610126

De Frenne P et al (2009) Unravelling the effects of temperature, latitude and local environment on the reproduction of forest herbs. Glob Ecol Biogeogr 18:641-651

Deen W, Hunt T, Swanton CJ (1998) Influence of temperature, photoperiod, and irradiance on the phenological development of common ragweed (Ambrosia artemisiifolia). Weed Sci 46:555-560

Dickerson CT, Sweet RD (1971) Common ragweed ecotypes. Weed Sci 19:64-66

DiTommaso A (2004) Germination behavior of common ragweed (Ambrosia artemisiifolia) populations across a range of salinities. Weed Sci 52:1002-1009

Dlugosch KM, Parker IM (2008) Founding events in species invasions: genetic variation, adaptive evolution, and the role of multiple introductions. Mol Ecol 17:431-449

Donohue K, de Casas RR, Burghardt L, Kovach K, Willis CG (2010) Germination, postgermination adaptation, and species ecological ranges. Annu Rev Ecol Evol Syst 41:293-319

Dukes JS, Mooney HA (1999) Does global change increase the success of biological invaders? Tree Physiol 14:135-139

Ebeling SK, Welk E, Auge H, Bruelheide H (2008) Predicting the spread of an invasive plant: combining experiments and ecological niche model. Ecography 31:709-719

Ellstrand NC, Schierenbeck KA (2000) Hybridization as a stimulus for the evolution of invasiveness in plants? Proc Natl Acad Sci 97:7043-7050

Erfmeier A, Bruelheide H (2005) Invasive and native Rhododendron ponticum populations: is there evidence for genotypic differences in germination and growth? Ecography 28:417-428

Forcella F, Wilson RG, Dekker J, Kremer RJ, Cardina J, Anderson RL, Alm D, Renner KA, Harvey RG, Sharon C, Buhler DD (1997) Weed seed bank emergence across the corn belt. Weed Sci 45:67-76

Franklin J (1995) Predictive vegetation mapping: geographic modelling of biospatial patterns in relation to environmental gradients. Prog Phys Geogr 19:474-499

Fumanal B, Chauvel B, Bretagnolle F (2007) Estimation of pollen and seed production of common ragweed in France. Ann Agric Environ Med 14:233-236

Genton BJ, Shykoff JA, Giraud T (2005) High genetic diversity in French invasive populations of common ragweed, Ambrosia artemisiifolia, as a result of multiple sources of introduction. Mol Ecol 14:4275-4285
Gerhold P et al (2011) Phylogenetically poor plant communities receive more alien species, which more easily coexist with natives. Am Nat 177:668-680

Gladieux P, Giraud T, Kiss L, Genton B, Jonot O, Shykoff J (2011) Distinct invasion sources of common ragweed (Ambrosia artemisiifolia) in Eastern and Western Europe. Biol Invasions 13:933-944

Gregor T, Bönsel D, Starke-Ottich I, Tackenberg O, Wittig R, Zizka G (2013) Epilobium brachycarpum: a fast-spreading species in Germany. Tuexenia 33:259-283

Grime JP, Mason G, Curtis AV, Rodman J, Band SR (1981) A comparative study of germination characteristics in a local flora. $\mathrm{J}$ Ecol 69:1017-1059

Guillemin JP, Gardarin A, Granger S, Reibel C, Munier-Jolain N, Colbach N (2013) Assessing potential germination period of weeds with base temperatures and base water potentials. Weed Res 53:76-87

Haylock MR, Hofstra N, Klein Tank AMG, Klok EJ, Jones PD, New M (2008) A European daily high-resolution gridded dataset of surface temperature and precipitation. J Geophys Res (Atmospheres) 113:D20119

Hierro JL, Maron JL, Callaway RM (2005) A biogeographical approach to plant invasions: the importance of studying exotics in their introduced and native range. J Ecol 93:5-15

Hierro JL, et al. (2009) Germination responses of an invasive species in native and non-native ranges. Oikos 118:529-538

Hodgins KA, Rieseberg L (2011) Genetic differentiation in life-history traits of introduced and native common ragweed (Ambrosia artemisiifolia) populations. J Evol Biol 24:2731-2749

Joshi J et al (2001) Local adaptation enhances performance of common plant species. Ecol Lett 4:536-544

Kazinczi G, Béres I, Novák R, Bíró K, Pathy Z (2008) Common ragweed (Ambrosia artemisiifolia): a review with special regards to the results in Hungary. I. Taxonomy, origin and distribution, morphology, life cycle and reproduction strategy. Herbologia 9:55-91

Keane RM, Crawley MJ (2002) Exotic plant invasions and the enemy release hypothesis. Trends Ecol Evol 17:164-170

Kollmann J, Banuelos MJ (2004) Latitudinal trends in growth and phenology of the invasive alien plant Impatiens glandulifera (Balsamiaceae). Divers Distrib 10:377-384

Kowarik I (ed) (2010) Biologische Invasionen. Neophyten und Neozoen in Mitteleuropa, 2. Ulmer, Stuttgart

Kriticos DJ, Sutherst RW, Brown JR, Adkins SW, Maywald GF (2003) Climate change and the potential distribution of an invasive alien plant: Acacia nilotica ssp. indica in Australia. J Appl Ecol 40:111-124

Lavergne S, Molofsky J (2007) Increased genetic variation and evolutionary potential drive the success of an invasive grass. Proc Natl Acad Sci 104:3883-3888

Lee CE (2002) Evolutionary genetics of invasive species. Trends Ecol Evol 17:386-391

Leger EA, Rice KJ (2007) Assessing the speed and predictability of local adaptation in invasive California poppies (Eschscholzia californica). J Evol Biol 20:1090-1103

Leiblein-Wild MC, Tackenberg O Phenotypic variation of 38 invasive Ambrosia artemisiifolia populations measured in a common garden experiment. Biological Invasions (under review)

Makra L, Juhasz M, Borsos E, Beczi R (2004) Meteorological variables connected with airborne ragweed pollen in Southern Hungary. Int J Biometeorol 49:37-47

Mandak B (2003) Germination requirements of invasive and noninvasive Atriplex species: a comparative study. Flora 198:45-54

Merrill KR, Meyer SE, Coleman CE (2012) Population genetic analysis of Bromus tectorum (Poaceae) indicates recent range expansion may be facilitated by specialist genotypes. Am J Bot 99:529-537 
Montague JL, Barrett SCH, Eckert CG (2008) Re-establishment of clinal variation in flowering time among introduced populations of purple loosestrife (Lythrum salicaria, Lythraceae). J Evol Biol 21:234-245

Parmesan C (2006) Ecological and evolutionary responses to recent climate change. Annu Rev Ecol Evol Syst 37:637-669

Payne WW, Kleinschmidt WF (1961) Maintaining ragweed cultures. J Allergy 32:241-245

Pickett ST, Baskin JM (1973) The role of temperature and light in the germination behavior of Ambrosia artemisiifolia. Bull Torrey Bot Club 100:165-170

Prentis PJ, Wilson JRU, Dormontt EE, Richardson DM, Lowe AJ (2008) Adaptive evolution in invasive species. Trends Plant Sci 13:288-294

Radford IJ, Cousens RD (2000) Invasiveness and comparative lifehistory traits of exotic and indigenous Senecio species in Australia. Oecologia 125:531-542

Rathcke B, Lacey EP (1985) Phenological patterns of terrestrial plants. Annu Rev Ecol Syst 16:179-214

Reinhardt F, Herle M, Bastiansen F, Streit B (2003) Economic impact of the spread of alien species in Germany. UBA-FB, Federal Environmental Agency, Berlin

Sakai AK et al (2001) The population biology of invasive species. Annu Rev Ecol Syst 32:305-332
Sala OE et al (2000) Global biodiversity scenarios for the year 2100 . Science 287:1770-1774

Skálová H, Moravcová L, Pysek P (2011) Germination dynamics and seedling frost resistance of invasive and native Impatiens species reflect local climatic conditions. Perspect Plant Ecol Evol Syst 13:173-180

Taramarcaz P, Lambelet B, Clot B, Keimer C, Hauser C (2005) Ragweed (Ambrosia) progression and its health risks: will Switzerland resist this invasion? Swiss Med Wkly 135:538-548

Thuiller W, Richardson DM, Rouget M, Proches S, Wilson JRU (2006) Interactions between environment, species traits, and human uses describe patterns of plant invasions. Ecology $87: 1755-1769$

Toole EH, Brown E (1946) Final results of the Durvel buried seed experiment. J Agric Res 72:201-210

Weber E, Schmid B (1998) Latitudinal population differentiation in two species of Solidago (Asteraceae) introduced into Europe. Am J Bot 85:1110-1121

Willemsen RW (1975) Effect of stratification temperature and germination temperature on germination and the induction of secondary dormancy in common ragweed seeds. Am J Bot 62:1-5

Xia HB, Xia H, Ellstrand NC, Yang C, Lu BR (2011) Rapid evolutionary divergence and ecotypic diversification of germination behavior in weedy rice populations. New Phytol 191:1119-1127 